\title{
Doença renal medular cística em uma cadela Yorkshire Terrier: relato de caso
}

[Cystic medullary renal disease in a Yorkshire Terrier bitch: a case report]

\author{
M.A.R.Feliciano ${ }^{1}$, C.A.L. Leite ${ }^{2}$, T. Silveira ${ }^{3}$, G.A.O. Cavalcanti ${ }^{4}$, M.S. Varaschin ${ }^{2}$, W.R.R. Vicente ${ }^{1}$ \\ ${ }^{1}$ Faculdade de Ciências Agrárias e Veterinárias - UNESP - Jaboticabal, SP \\ ${ }^{2}$ Departamento de Medicina Veterinária - UFLA - Lavras, MG \\ ${ }^{3}$ Médica veterinária autônoma \\ ${ }^{4}$ Aluno de pós-graduação - EV-UFMG - Belo Horizonte, MG
}

\begin{abstract}
RESUMO
Uma cadela da raça Yorkshire Terrier apresentou hematêmese, distensão abdominal, poliúria e polidipsia. Após o exame clínico do paciente, estabeleceu-se a suspeita clínica de nefropatia. Os resultados dos exames laboratoriais revelaram anemia normocítica normocrômica e concentrações séricas de uréia $(306 \mathrm{mg} / \mathrm{dl})$ e de creatinina $(3,6 \mathrm{mg} / \mathrm{dl})$ acima dos valores de referência. Ao ultra-som bidimensional observaram-se áreas císticas hipoecóicas e anecóicas, padrão renal hipercogênico e perda da relação corticomedular. À necropsia, a região medular apresentou grande quantidade de cistos pequenos em meio a tecido conjuntivo fibroso. A lesão tubulointersticial cortical foi a responsável pela insuficiência renal resultante. Firmou-se diagnóstico de nefrite tubulointersticial.
\end{abstract}

Palavras-chave: cão, doença renal medular cística, nefrologia

\begin{abstract}
A Yorkshire Terrier bitch presented hematemesis, abdominal distention, poliuria, and polidipsia. After clinical examination, it was established a clinical suspect of nephropathy. The complementary exams showed normochromic and normocytic anemia and serum concentrations of ureia (306mg/dl) and creatinine $(3.6 \mathrm{mg} / \mathrm{dl})$ above the references values. At two-dimensional ultrasound hipoechoic and anechoic cystic areas were observed, as well as hiperechogenic renal pattern and corticomedullary ratio loss. At necropsy, the medullary region presented many small cysts in a fibrous connective tissue. Cortical tubulointesticial lesion was responsible to the resulting renal failure. It was established a tubulointersticial nephritis diagnosis.
\end{abstract}

Keywords: dog, cystic medullary renal disease, nephrology

\section{INTRODUÇ̃̃O}

Em relação às doenças renais císticas não hereditárias nos animais domésticos, Forrester (2003) cita a existência de: (1) doença policística familiar em cães da raça Cairn Terrier e gatos de pêlo longo, ocorrendo nefromegalia e cistos associados a outros tecidos (hepático e pancreático); (2) doença cística renal adquirida, que se desenvolve em animais com insuficiência renal crônica; e (3) pseudocistos perinéfricos, doença rara que acomete gatos e cuja patogenia é desconhecida. Já na doença renal policística hereditária da raça Bull Terrier, os cistos ocorrem nos glomérulos, causando sua atrofia, entre outras alterações visíveis (O’Leary et al., 2002). Takahashi et al. (2005) citam a doença glomerulocística como sendo de ocorrência ocasional em potros e cães da raça Collie.

As doenças renais císticas em seres humanos são classificadas em: displasia renal cística, doença renal policística autossômica dominante (adultos), doença renal policística autossômica recessiva (crianças), doença cística medular ("rins em esponja medular" e

Recebido em 20 de julho de 2007

Aceito em 26 de maio de 2008

E-mail: marcusfeliciano@yahoo.com.br 
nefronoftise), doença cística adquirida, cistos renais localizados, cistos renais em síndromes de malformações hereditárias, doença glomerulocística e cistos renais extraparenquimatosos (Thomsen et al., 1997).

As manifestações fisiopatogênicas dos cistos, em animais e seres humanos, são lesões em túbulos distais, ruptura da membrana basal tubular, atrofia tubular crônica envolvendo medula e córtex e fibrose intersticial (Grantham, 1992; Carone et al., 1995; Sakurai e Nigam, 1998).

Em cães, o início da doença renal policística familiar ocorre, geralmente, dos seis meses aos cinco anos, e a maioria das doenças renais resulta em insuficiência renal em idade jovem (DiBartola, 2004).

De acordo com O'Leary et al. (2002) e Bittencourt et al. (2004), os achados clínicos mais comuns nas doenças policísticas renais são poliúria, polidipsia, anorexia, perda de peso, vômitos, gastrite urêmica, halitose, hipertensão pulmonar, dispnéia, letargia, tremores, convulsões, distensão abdominal, nefromegalia à palpação abdominal e nefralgia. Os achados laboratoriais incluem acidose metabólica, anemia arregenerativa normocítica normocrômica, azotemia, hiperamilasemia, hiperlipasemia, hiper ou hipocalcemia, hipermagnesemia, hipocalcemia, aumento de creatinina sérica e proteinúria (Blowey et al., 1996).

Ao exame ultra-sonográfico, verificam-se rins de tamanhos normais ou diminuídos, aumento de ecogenicidade renal, presença de cistos com contorno arredondado a ovóide, conteúdo anecóico e paredes finas (Levine et al., 1997).

A maioria das doenças císticas é progressiva, culminando com o óbito. O tratamento fica limitado ao controle clínico conservador da insuficiência renal. Muitas vezes, os animais são assintomáticos até os cistos atingirem um tamanho que cause insuficiência renal (DiBartola, 2004).

O objetivo deste relato é descrever um caso de doença renal medular cística em cão da raça Yorkshire Terrier.

\section{CASUÍSTICA}

Uma cadela da raça Yorkshire Terrier, com três anos de idade e peso de $3 \mathrm{~kg}$, apresentou histórico de apatia, paresia dos membros posteriores e anorexia há mais de uma semana. $\mathrm{O}$ proprietário relatou que no dia anterior à consulta o animal apresentou episódios de hematêmese, distensão abdominal, poliúria e polidipsia.

Após o exame clínico da paciente, estabeleceuse a suspeita clínica de nefropatia. Para confirmar, especificar e verificar o grau da nefropatia, realizaram-se avaliação da dosagem sérica de uréia e creatinina, hemograma, trombograma e exame ultra-sonográfico renal. Ao exame físico, o animal apresentava hipotermia, mucosas hipocoradas, desidratação acentuada $(12 \%)$, tempo de reperfusão capilar aumentado e dor à palpação abdominal direta, relacionada à região renal.

Os resultados dos exames laboratoriais revelaram anemia normocítica normocrômica e concentração sérica de uréia $(306 \mathrm{mg} / \mathrm{dl})$ e creatinina $(3,6 \mathrm{mg} / \mathrm{dl})$ acima dos valores de referência. Ao exame ultra-sonográfico bidimensional, observaram-se áreas císticas hipoecóicas e anecóicas, padrão renal hipercogênico e com perda da relação corticomedular (Fig. 1).

Após a confirmação da nefropatia, associada com insuficiência renal, foi instituído tratamento à base de fluidoterapia parenteral (fluido glicofisiológico ${ }^{1}$ ), diurético (furosemida ${ }^{2}$ $2 \mathrm{mg} / \mathrm{kg}$ por via intravenosa a cada oito horas), antibiótico (enrofloxacina ${ }^{3} 10 \mathrm{mg} / \mathrm{kg}$ por via subcutânea a cada 12 horas), protetor gástrico (pantoprazol ${ }^{4} 0,7 \mathrm{mg} / \mathrm{kg}$ por via intravenosa a cada 24 horas), antiemético (metoclopramida ${ }^{5}$ $0,5 \mathrm{mg} / \mathrm{kg}$ por via subcutânea a cada oito horas) e suplementação com vitamina $\mathrm{C}^{6}$ e complexo $\mathrm{B}^{7}$.

\footnotetext{
${ }^{1}$ Solução de glicose a $5 \%$ em solução fisiológica de cloreto de sódio a $0,9 \%$ - Sanobiol

${ }^{2}$ Furosemida 20mg/2ml - Vital Brazil

${ }^{3}$ Baytril injetável 5\% - Bayer

${ }^{4}$ Pantozol EV 40mg/10ml - Altana

${ }^{5}$ Metoclopramida $10 \mathrm{mg} / 2 \mathrm{ml}$ - Green Pharma

${ }^{6}$ Ceviton - Ariston

${ }^{7}$ Complexo B - Haller
} 


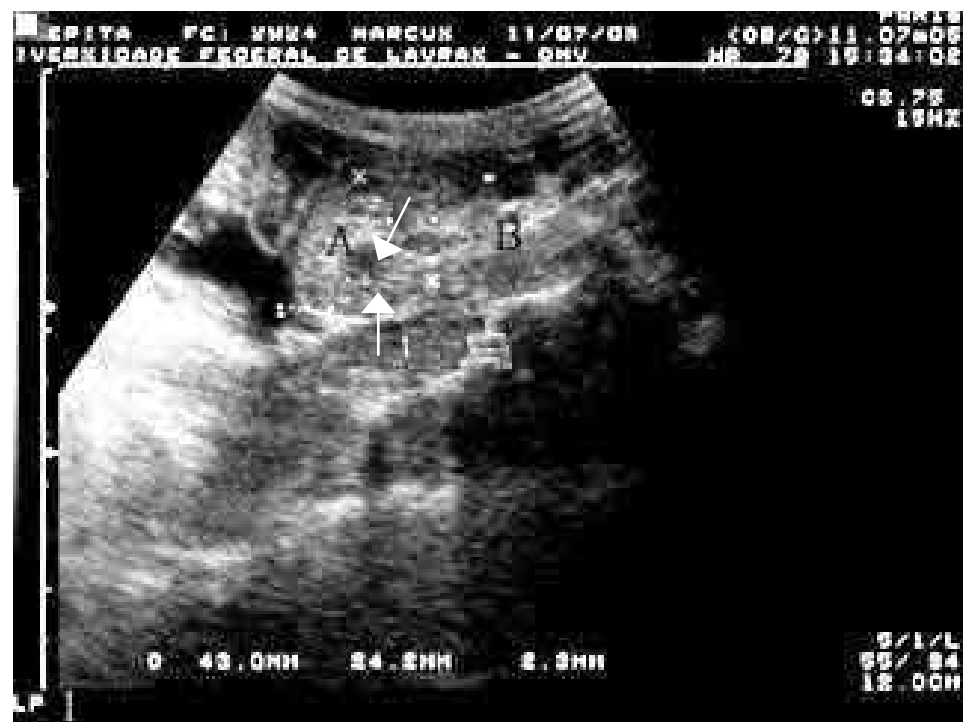

Figura 1. Imagem ultra-sonográfica de cadela com doença medular cística, apresentando rim esquerdo com áreas císticas anecóicas e hipoecóicas (setas), padrão renal hiperecogênico (A) e perda da relação corticomedular (B).

Entretanto, o animal não apresentou melhora e veio a óbito.

$\mathrm{Na}$ necropsia foram colhidos fragmentos dos rins, pulmão e estômago e fixados em formalina a $10 \%$, processados rotineiramente para histologia e corados com hematoxilina e eosina. As lâminas processadas foram avaliadas por microscopia óptica.

À necropsia, observaram-se rins reduzidos de tamanho, firmes, com superfície irregular, esbranquiçados (principalmente na região correspondente à medular) e pouco volume de parênquima cortical. A região medular apresentava-se com grande quantidade de cistos pequenos em meio a um tecido conjuntivo fibroso (Fig. 2). O animal também apresentava lesões características de uremia, como ulceração bilateral na região ventral da língua, ulcerações multifocais no estômago (gastropatia urêmica) e pulmões armados que não colabaram mediante exposição ao ar, no qual, microscopicamente, foram observadas áreas multifocais de calcificação no interstício alveolar (pneumopatia urêmica). Microscopicamente, os rins apresentavam região cortical com intensa vacuolização do citoplasma das células dos túbulos contorcidos proximais, com sinais de nefrite intersticial multifocal linfoplasmocitária e fibrose de interstício. Vários glomérulos apresentaram hialinização e espessamento de cápsula e tufo. Na região medular, observaramse infiltrado linfoplasmocitário, focos de macrófagos espumosos no interstício e grande quantidade de cistos de vários tamanhos, recobertos por epitélio achatado (Fig. 3, 4 e 5).

\section{DISCUSSÃO}

Os achados do exame físico são inespecíficos e podem sugerir nefropatia segundo O'Leary et al. (2002) e Bittencourt et al. (2004). O animal não apresentava histórico familiar de doença renal policística. De acordo com Blowey et al. (1996), Thomsen et al. (1997) e Hildebrandt e Omram (2001), os exames laboratoriais não especificam qual o tipo de doença renal que o paciente apresenta. Os achados ultra-sonográficos sugerem doença renal medular cística, segundo Levine et al. (1997) e Carvalho et al. (2003).

O tratamento proposto foi consistente com o proposto por DiBartola (2004), visando a minimizar os efeitos da insuficiência renal instalada.

Semelhante à proposição de Sakurai e Nigam (1998) e Calvet e Grantham (2001), embora a presença de cistos medulares seja importante, a lesão tubulointersticial cortical é a responsável pela insuficiência renal resultante, optando por denominar esta alteração como uma nefrite tubulointersticial. 


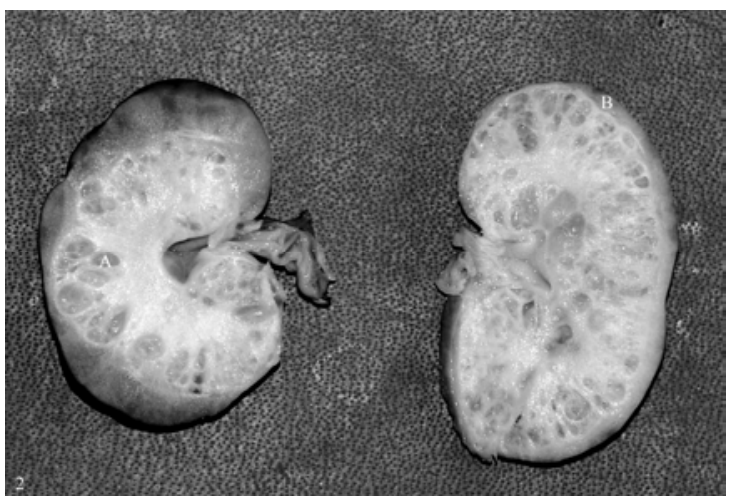

Figura 2. Aspectos macroscópicos dos rins, com cistos restritos à região medular (A) e atrofia por compressão da região cortical $(\mathrm{B})$, em cadela com doença medular cística.

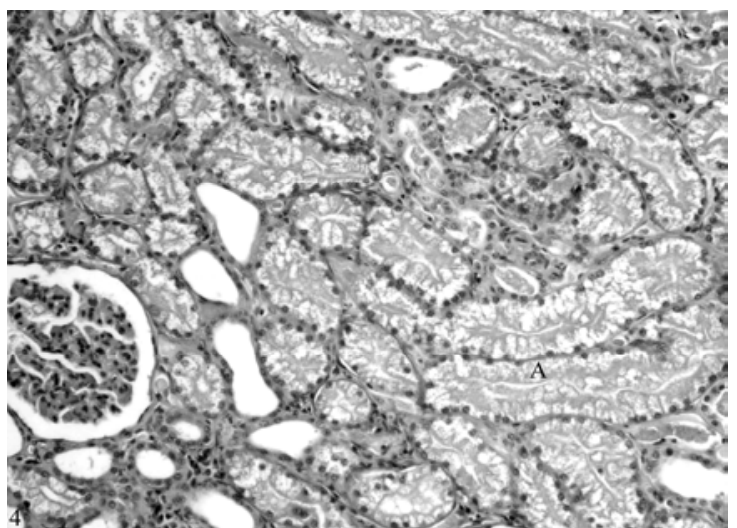

Figura 4. Região cortical renal evidenciando acentuada degeneração tubular (A) em cadela com doença medular cística (400x).

\section{CONCLUSÕES}

Comparando-se achados clínicos, histológicos e exames complementares, conclui-se que a doença renal medular cística diagnosticada no cão deste relato é semelhante ao complexo nefronoftise-doença medular cística que ocorre no ser humano. Trata-se, portanto, da primeira citação da doença em medicina veterinária em cão da raça Yorkshire Terrier.

\section{REFERÊNCIAS BIBLIOGRÁFICAS}

BITTENCOURT, E.; MORAES, P.R.; GOIOZO, P.F.I. et al. Nefropatia juvenil progressiva associada à displasia renal em Lhasa

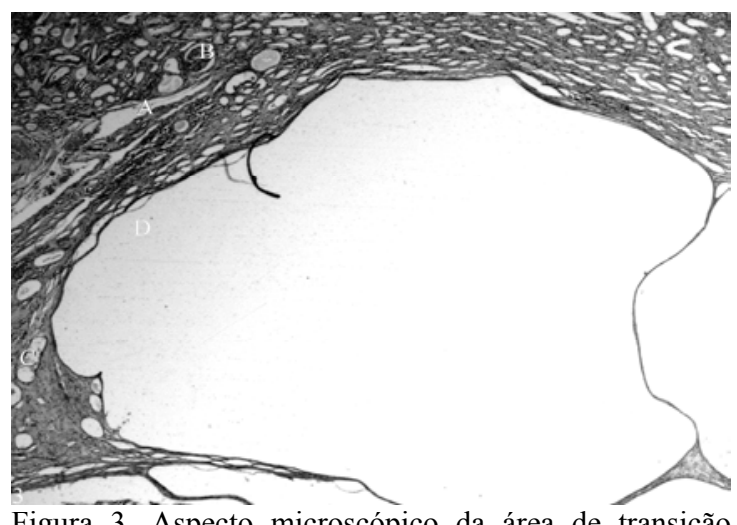

Figura 3. Aspecto microscópico da área de transição entre zonas cortical e glomerular renal, em cadela com doença medular cística (A). Observar alguns glomérulos (B) preservados, focos de degeneração tubular (C) na cortical e cistos na região medular (D) (200x).

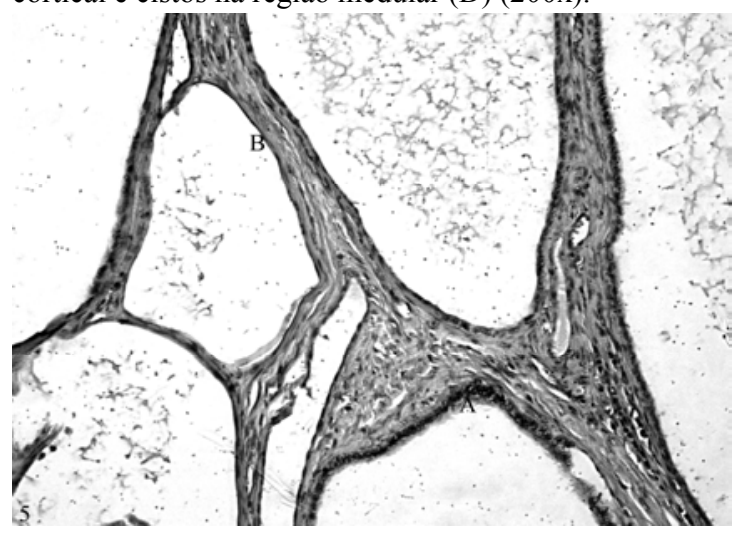

Figura 5. Região medular renal evidenciando o epitélio de aspecto normal (A) e achatado (B) dos cistos medulares, em cadela com doença medular cística (400x).

Apso: relato de caso. Clin. Vet., v.11, p.24-26, 2004.

BLOWEY, D.L.; QUERFELD, U.; GEARY, D. et al. Ultrasound findings in juvenile nephronophthisis. Pediatr. Nephrol., v.1, p.2224, 1996.

CALVET, J.P.; GRANTHAM, J.J. The genetics and physiology of polycystic kidney disease. Semin. Nephrol., v.21, p.107-123, 2001.

CARONE, F.A.; BACALLAO, R.; KANWAR, Y.S. The pathogenesis of polycystic kidney disease. Histol. Histopathol., v.10, p.213-221, 1995.

CARVALHO, T.N.; ARAÚJO JR., T.R.; FRAGUAS FILHO, S.R. et al. Doença cística medular do rim: relato de um caso diagnosticado 
por ultra-sonografia e tomografia computadorizada. Radiol. Bras., v.36, p.32-36, 2003.

DiBARTOLA, S.P. Doença renal familiar em cães e gatos. In: ETTINGER, S.J.; FELDMAN, E.C. (Eds). Tratado de medicina interna veterinária: doenças do cão e do gato. 5.ed. Rio de Janeiro: Guanabara-Koogan, 2004. p.17891794.

FORRESTER, S.D. Nefropatias e uretropatias. In: BICHARD, S. J.; SHERDING, R. G. (Eds) Manual Saunders: clínica de pequenos animais, 2.ed. São Paulo: Roca, 2003. p.1001-1034.

GRANTHAM, J.J. Polycystic kidney disease: etiology and pathogenesis. Hosp. Pract., v.27, p.51-59, 1992.

HILDEBRANDT, F.; OMRAM, H. New insights: nephronophthisis-medullary cystic kidney disease. Pediatr. Nephrol., v.2, p.168176,2001
LEVINE, E.; HARTMAN, D.S.; MEILSTRUP, J.W. et al. Current concepts and controversies in imaging of renal cystic diseases. Urol. Clin. N. Am., v.24, p.523-543, 1997.

O'LEARY, C.A.; GHODDUSI, M.; HUXTABLE, C.R. Renal pathology of polycystic kidney disease and concurrent hereditary nephritis in Bull Terriers. Aust. Vet. J., v.80, p.353-361, 2002.

SAKURAI, H.; NIGAM, S.K. Cystic disease. Kid. Int., v.54, p.14, 1998.

TAKAHASHI, M.; MORITA,T.; SAWADA, M. et al. Glomerulocystic kidney in a domestic dog. J. Comp. Pathol., v.133, p.205-208, 2005.

THOMSEN, H.S.; LEVINE, E.; MEILSTRUP, J.W. et al. Renal cystic diseases. Eur. Radiol., v.7, p.1267-1275, 1997. 